\title{
Correction to: Foliar fertilization with micronutrients improves Stevia rebaudiana tolerance to salinity stress by improving root characteristics
}

\author{
Mehdi Aghighi Shahverdi ${ }^{1}$ [D $\cdot$ Heshmat Omidi ${ }^{1} \cdot$ Christos A. Damalas $^{2}$
}

Published online: 29 December 2021

(c) The Author(s), under exclusive licence to Botanical Society of Sao Paulo 2021

\section{Correction to: Brazilian Journal of Botany (2020) 43:55-65 https://doi.org/10.1007/s40415-020-00588-6}

In this article Mehdi Aghighi Shahverdi was incorrectly denoted as the corresponding author but it should have been Heshmat Omidi.

The original article has been corrected.

Publisher's Note Springer Nature remains neutral with regard to jurisdictional claims in published maps and institutional affiliations.

The original article can be found online at https://doi.org/10.1007/ s40415-020-00588-6.

Heshmat Omidi

omidi@shahed.ac.ir

Mehdi Aghighi Shahverdi

aghighim@shahed.ac.ir

Christos A. Damalas

chris.damalas@yahoo.gr

1 Agricultural College and Medicinal Plant Research Center, Shahed University, Tehran, Iran

2 Department of Agricultural Development, Democritus University of Thrace, Orestiada, Greece 